\title{
Macroeconomic Modeling with Asymmetric Vector Autoregressions
}

\author{
John W. Keating ${ }^{*}$
}

Abstract: 


\section{Introduction}

Vector autoregression (VAR) models have become widely used in applied economic research since Sims (1980) pioneered this approach. In a VAR each variable is regressed against the same number of lags of every variable. In other words, VAR lag specifications are symmetrical. Unfortunately, VARs often estimate a large number of statistically insignificant coefficients, and therefore the impulse responses and variance decompositions constructed from the reduced-form coefficients will often be imprecisely determined. As Runkle (1987,p.442) asserts ${ }^{1}$ "VARs may let the data speak for themselves, but the data are not talking very loudly."

Hsiao's (1981) method and Litterman's (1986) Bayesian approach ${ }^{2}$ are two popular alternatives to unconstrained VARs. Each imposes restrictions on the VAR's coefficients in an attempt to obtain more efficient estimates. While these approaches often generate superior forecasts, they may impose dynamic restrictions that interfere with an investigation of structural dynamics. For example, the dynamic specification obtained with Hsiao's procedure in general depends on the sequence explanatory variables are considered because significant regressors are kept in the model when testing additional regressors. Methods do exist for choosing the sequence of variables, but these techniques are based essentially on forecasting criteria, not on the model's ability to identify structural dynamics. On the other hand, Litterman imposes Bayesian prior restrictions on VAR coefficients. Because these prior restrictions are almost always based on forecasting performance instead of economic theory, ${ }^{3}$ parameter estimates from Bayesian VARs are likely to be biased. Bias may be acceptable in forecasting, but biased structural parameter estimates are undesirable if the goal is to answer questions about macroeconomic structure.

This paper investigates an alternative way of constraining reduced-form coefficients called the "asymmetric vector autoregression" (AVAR). In an AVAR system each equation has the same explanatory variables and each variable may have a different number of lags. For example, each equation in a bivariate AVAR could have three lags of output and six lags of money. Although a VAR is a special kind of AVAR 
system, AVAR models permit more flexibility in modeling dynamic systems.

Section 2 derives the AVAR model from a general linear structure. A particular economic structure is developed in the third section. These economic restrictions are used in section 4 to identify structure from the reduced-form AVAR and VAR models. Since all possible AVAR models are estimated in this example, the chosen AVAR model does not depend on the sequence of specification tests.

Parameter estimates from the AVAR models frequently have smaller standard errors than the VAR, particularly the long-run structural parameters. In many instances the reduction in standard error is substantial, suggesting efficiency gains may be obtained with AVAR models. The response functions and the structural parameters are qualitatively similar in all the empirical models. In addition, point estimates from the AVAR selected by the Akaike information criterion and from the VAR are typically of comparable size. Hence, this AVAR model yields economic implications which are remarkably similar to those of the VAR, while obtaining standard errors that are smaller or of comparable size.

The paper also addresses questions about macroeconomic structure. The empirical models are used to investigate if money supply influences the macroeconomy through a liquidity effect, to determine the contribution made by various structural shocks to economic fluctuations, and to test the hypothesis that some kinds of aggregate demand shocks have a long-run effect on output.

\section{Asymmetric Dynamics in VAR Models}

Suppose $\mathrm{Z}_{\mathrm{t}}$ is a vector of $\mathrm{N}$ variables and our purpose is to identify the responses of each variable to the structural shocks $\varepsilon_{\mathrm{t}}$ :

$$
\mathrm{Z}_{\mathrm{t}}=\Theta(\mathrm{L}) \varepsilon_{\mathrm{t}}
$$


where $\varepsilon_{\mathrm{t}}$ is a vector of $\mathrm{N}$ white noise shocks, $\mathrm{E}\left[\varepsilon_{\mathrm{t}} \varepsilon_{\mathrm{t}}^{\prime}\right]=\Sigma_{\epsilon}$ and $\Theta(\mathrm{L})=\sum_{\mathrm{q}=0}^{\infty} \Theta_{\mathrm{q}} \mathrm{L}^{\mathrm{q}}$

where $\Sigma_{\epsilon}$ and $\Theta_{\mathrm{q}}$ are $\mathrm{N} \times \mathrm{N}$ matrices. If $\Theta(\mathrm{L})$ is invertible, (1) can be pre-multiplied by $\Theta(\mathrm{L})^{-1}$ to obtain a structural autoregressive representation:

$$
\Gamma(\mathrm{L}) \mathrm{Z}_{\mathrm{t}}=\varepsilon_{\mathrm{t}}
$$

where $\Gamma(\mathrm{L})=\Theta(\mathrm{L})^{-1}$ and $\Gamma(0)=\Theta_{0}^{-1}$ by construction. Equation (2) is best thought of as a dynamic simultaneous system of structural equations. Pre-multiplying (2) by $\Theta_{0}$ yields,

$$
\beta(\mathrm{L}) \mathrm{Z}_{\mathrm{t}}=\mathrm{e}_{\mathrm{t}}
$$

with reduced-form coefficients, $\beta(L)=\Theta_{0} \Gamma(L)$, and the vector of one-step forecast errors, $e_{t}=\Theta_{0} \varepsilon_{t}$. Therefore, equation (3) writes each variable in $\mathrm{Z}$ as a function of lags of $\mathrm{Z}$ and the one-step forecast error to that variable. Elements in $\Gamma(\mathrm{L})$ can be written as

$$
\Gamma^{\mathrm{kj}(\mathrm{L})}=\gamma_{0 \mathrm{kj}}+\gamma_{1 \mathrm{kj}} \mathrm{L}+\gamma_{2 \mathrm{kj}} \mathrm{L}^{2}+\ldots+\gamma_{\mathrm{n}_{\mathrm{kj}} \mathrm{kj}} \mathrm{L}^{\mathrm{n}}{ }_{\mathrm{kj}}
$$

where each $\gamma_{\mathrm{qkj}}$ is a scalar parameter for $\mathrm{q}=1,2, \ldots, \mathrm{n}_{\mathrm{kj}}$ with $\mathrm{n}_{\mathrm{kj}}$ the length of a particular lag polynomial. The reduced-form coefficients are linear combinations of elements in $\Gamma(\mathrm{L})$ with lags of the $\mathrm{j}$-th variable in the $\mathrm{i}$ th variable's equation given by

$$
\beta^{\mathrm{ij}}(\mathrm{L})=\sum_{\mathrm{k}=1}^{\mathrm{N}} \Theta_{0}^{\mathrm{ik}} \Gamma^{\mathrm{kj}}(\mathrm{L})
$$

Each element in $\Gamma(\mathrm{L})$ has the same maximum number of lags if $n_{k j}=n$ for all $(k, j)$. In this case, each $\beta^{\mathrm{ij}}(\mathrm{L})$ is of lag length $\mathrm{n}$ because each is composed of $\mathrm{N}$ lag polynomials of that same length. However, there is no reason to assume $\Gamma(\mathrm{L})$ has this symmetry, and in principle, each lag polynomial in $\Gamma(\mathrm{L})$ may be of arbitrary length. The lag length for $\beta^{\mathrm{ij}}(\mathrm{L}), v_{\mathrm{ij}}$, is determined by the longest lag polynomial from the elements in $\Gamma(\mathrm{L})$ used to construct $\beta^{\mathrm{ij}}(\mathrm{L})$ : 


$$
v_{\mathrm{ij}}=\operatorname{Max}\left\{\mathrm{n}_{1 \mathrm{j}}, \mathrm{n}_{2 \mathrm{j}}, \ldots, \mathrm{n}_{\mathrm{Nj}}\right\}
$$

From equation (5), it is obvious that $\beta^{1 \mathrm{j}}(\mathrm{L}), \beta^{2 \mathrm{j}}(\mathrm{L}), \ldots$ and $\beta^{\mathrm{Nj}}(\mathrm{L})$ are each linear combinations of the same $\mathrm{N}$ lag polynomials, $\Gamma^{\mathrm{lj}}(\mathrm{L}), \Gamma^{2 \mathrm{j}}(\mathrm{L}), \ldots$ and $\Gamma^{\mathrm{Nj}}(\mathrm{L})$. Hence, the number of lags for variable $\mathrm{j}$ is the same in each equation of the reduced form because $v_{i j}$ is the same for $\mathrm{i}=1,2, \ldots, \mathrm{N}$. However, for each variable $\mathrm{j}$ the maximum is over a different set of lag polynomials. Therefore, (6) implies that each $\mathrm{j}$ may have a different lag length. Since econometricians are almost always incapable of knowing a priori that the underlying structural dynamics will necessarily yield a symmetric VAR reduced form, they should at least consider the possibility of asymmetric dynamics.

The asymmetric VAR model is defined as a vector autoregression in which each variable in the model may have a unique number of lags. AVAR models have the consecutive lag specification found also in symmetric VARs whereby all lags from the first lag to some finite upper bound are used as regressors. Statistical criteria are used to identify asymmetric lag structures. If the number of lags for the $\mathrm{N}$ variable model range from 1 to $\mathrm{M}$, there are $\mathrm{M}^{\mathrm{N}}$ possible AVAR specifications. AVAR models share with VARs the property that OLS estimates are consistent and efficient because in either type of model each equation has the same regressors. The class of AVAR models encompasses symmetric VARs, yet permits more flexibility in specifying the dynamics. Hence, AVAR models are likely to obtain fewer insignificant coefficients and more efficient parameter estimates. ${ }^{4}$

AVAR models are consistent with an important theoretical result used to motivate VARs. Sims (1980,p.3) argued that in a system of structural equations "any variable which appears on the right hand side of one of these equations belongs in principle on the right hand side of all of them", and this restricts $\mathrm{n}_{1 \mathrm{j}}=\mathrm{n}_{2 \mathrm{j}}=\ldots=\mathrm{n}_{\mathrm{Nj}}$ in equation (2). As previously shown, these restrictions constrain lags of the $\mathrm{j}$-th variable to be the same in each equation of the reduced form, but they do not necessarily force lags to be identical for every j. Therefore, VAR modelers may also find AVAR specifications worthy of consideration. 


\section{Structural Identifying Restrictions}

Identification assumptions are required if one wishes to structurally interpret a reduced-form model. These restrictions will be used to compare and contrast the dynamic properties of AVAR and VAR models. The long-run identifying restrictions ${ }^{5}$ derived here are consistent with many New Keynesian and Real Business Cycle theories. None of the constraints apply directly to short-run dynamics. ${ }^{6}$ Note that all variables are in logarithmic form, except for interest rates.

Assume that a Cobb-Douglas production technology determines output (y) based on capital (k), labor hours (h) and a disturbance to technology $(\lambda)$ :

$$
\mathrm{y}_{\mathrm{t}}=\mathrm{a}_{\mathrm{h}} \mathrm{h}_{\mathrm{t}}+\mathrm{a}_{\mathrm{k}} \mathrm{k}_{\mathrm{t}}+\lambda_{\mathrm{t}} .
$$

Note that additive constants are omitted here and from all subsequent structural equations. This simplification is inconsequential because these constants disappear when variables are first-differenced to make the data stationary. ${ }^{7}$ Firms maximize profits by setting the marginal product of capital equal to the cost of capital. Assuming the log of the cost of capital is a linear function of the real interest rate (r), this first order condition for capital combined with (7) yields an implicit demand for capital:

$$
\mathrm{y}_{\mathrm{t}}-\mathrm{k}_{\mathrm{t}}=\mathrm{c}_{\mathrm{r}} \mathrm{r}_{\mathrm{t}}
$$

Firms also equate the marginal product of labor to the real wage (w) and (7) is used to simplify this implicit labor demand equation:

$$
\mathrm{y}_{\mathrm{t}}-\mathrm{h}_{\mathrm{t}}=\mathrm{w}_{\mathrm{t}} .
$$

Desired savings and labor supply equations are needed to construct equilibrium conditions for the capital and labor markets. Savings (s) is specified as a function of the real interest rate, real output and a savings disturbance $(\tau)$

$$
\mathrm{s}_{\mathrm{t}}=\mathrm{g}_{\mathrm{r}} \mathrm{r}_{\mathrm{t}}+\mathrm{g}_{\mathrm{y}} \mathrm{y}_{\mathrm{t}}+\tau_{\mathrm{t}}
$$

and labor supply is assumed to be a function of the real wage, the real rate of interest and a labor supply 
disturbance $(\eta):^{8}$

$$
\mathrm{h}_{\mathrm{t}}=\mathrm{b}_{\mathrm{w}} \mathrm{w}_{\mathrm{t}}+\mathrm{b}_{\mathrm{r}} \mathrm{r}_{\mathrm{t}}+\eta_{\mathrm{t}}
$$

An expression for equilibrium hours is derived using the labor demand function to eliminate wages from labor supply. This expression for hours and the demand for capital are then inserted into (7) to yield,

$$
y_{t}=\frac{\left[a_{h} b_{r}-\left(1+b_{w}\right) a_{k} c_{r}\right] r_{t}+a_{h} \eta_{t}+\left(1+b_{w}\right) \lambda_{t}}{\left(1+b_{w}\right)\left(1-a_{k}\right)-a_{h} b_{w}}
$$

which is essentially a modified version of the production function.

An IS equation is derived from the accounting identify that investment (i) equals savings: ${ }^{9}$

$$
\mathrm{i}_{\mathrm{t}}=\mathrm{s}_{\mathrm{t}} \text {. }
$$

Gross investment is equal to the change in the capital stock plus depreciation of capital. This identity can be used to show that

$$
\mathrm{i}_{\mathrm{t}}=\mathrm{k}_{\mathrm{t}} \text {, }
$$

noting that a constant term that depends on the mean depreciation rate and the average growth rate of capital is omitted. ${ }^{10}$ Equation (14) implies that investment and capital share a common trend. Using (14) to eliminate investment from (13), and then using (10) to eliminate savings and (8) to eliminate capital yields an equilibrium relationship between output, the real interest rate and the savings disturbance:

$$
r_{t}=\frac{\left(1-g_{y}\right) y_{t}-\tau_{t}}{c_{r}+g_{r}}
$$

Money demand is assumed to have the standard specification with real balances ( $\mathrm{m}$ ) a function of the nominal interest rate $(\mathrm{R})$, real output and a money demand disturbance $(\delta)$ :

$$
\mathrm{m}_{\mathrm{t}}=\mathrm{d}_{\mathrm{R}} \mathrm{R}_{\mathrm{t}}+\mathrm{d}_{\mathrm{y}} \mathrm{y}_{\mathrm{t}}+\delta_{\mathrm{t}}
$$

The nominal supply of money (M) is assumed a function of the nominal interest rate, output, real balances and a money supply disturbance $(\phi)$ :

$$
M_{t}=f_{R} R_{t}+f_{y} y_{t}+f_{m} m_{t}+\phi_{t} .
$$

Equations (12) and (15) employ the real interest rate while the money market equations use the 
nominal rate. The linear Fisher equation ${ }^{11}$ relates the nominal and real interest rates to expected inflation:

$$
R_{t}=r_{t}+E_{t}\left(P_{t+1}-P_{t}\right)
$$

with the logarithm of the price level given by $\mathrm{P}$. Inflation is assumed to be a stationary process. ${ }^{12}$ Under this assumption expected inflation must also be stationary. ${ }^{13}$ Based on many reported tests with postwar US data, the nominal interest rate is assumed to have a unit root. Given these assumptions for inflation and the nominal rate, the Fisher equation implies that a permanent change in $r$ is equivalent to a permanent change in R. Hence, the unobservable real rate does not need to be determined precisely to impose the long-run restrictions for the modified production function and the IS equation, ${ }^{14}$ and equations (15), (12), (16) and (17) can be written as

$$
\mathrm{AX}_{\mathrm{t}}=\zeta_{\mathrm{t}}
$$

where $X=(R, y, m, M)$ is the vector of variables, $A$ is the matrix of long-run structural parameters given by,

$$
A=\left[\begin{array}{cccc}
1 & -\alpha_{1} & 0 & 0 \\
-\alpha_{2} & 1 & 0 & 0 \\
-d_{R} & -d_{y} & 1 & 0 \\
-f_{R} & -f_{y} & -f_{m} & 1
\end{array}\right]
$$

$$
\text { with } \alpha_{1}=\frac{1-\mathrm{g}_{\mathrm{y}}}{\mathrm{c}_{\mathrm{r}}+\mathrm{g}_{\mathrm{r}}} \text { and } \alpha_{2}=\frac{\mathrm{a}_{\mathrm{h}} \mathrm{b}_{\mathrm{r}}-\left(1+\mathrm{b}_{\mathrm{w}}\right) \mathrm{a}_{\mathrm{k}} \mathrm{c}_{\mathrm{r}}}{\left(1+\mathrm{b}_{\mathrm{w}}\right)\left(1-\mathrm{a}_{\mathrm{k}}\right)-\mathrm{a}_{\mathrm{h}} \mathrm{b}_{\mathrm{w}}}
$$

and $\zeta$ is the vector of structural disturbances, $\zeta=\left[\zeta^{\text {is }}, \zeta^{\text {as }}, \delta, \phi\right]$

where the aggregate supply $\left(\zeta^{\text {as }}\right)$ and IS $\left(\zeta^{\text {is }}\right)$ disturbances are given by

$$
\zeta_{\mathrm{t}}^{\mathrm{as}}=\frac{\mathrm{a}_{\mathrm{h}} \eta_{\mathrm{t}}+\left(1+\mathrm{b}_{\mathrm{w}}\right) \lambda_{\mathrm{t}}}{\left(1+\mathrm{b}_{\mathrm{w}}\right)\left(1-\mathrm{a}_{\mathrm{k}}\right)-\mathrm{a}_{\mathrm{h}} \mathrm{b}_{\mathrm{w}}} \text { and } \zeta_{\mathrm{t}}^{\mathrm{is}}=\frac{-\tau_{\mathrm{t}}}{\mathrm{c}_{\mathrm{r}}+\mathrm{g}_{\mathrm{r}}}
$$

Since the IS equation is normalized on the interest rate, the IS disturbance is a decreasing function of the savings disturbance. The aggregate supply disturbance is a linear combination of technology and labor 
supply disturbances. If these two structural disturbances share a common dynamic propagation mechanism on macroeconomic variables, then the aggregate effect of these shocks can be identified by long-run restrictions. ${ }^{15}$ This condition is likely to be satisfied because labor supply and technology disturbances each affect the economy primarily through the production process.

This structural model based exclusively on long-run assumptions imposes far too many restrictions to adequately fit macroeconomic data. Furthermore, economic theories which allow each structural disturbance to have transitory effects on the cost of capital, the marginal product of capital, the marginal product of labor, desired savings, labor supply, money demand and money supply do exist. These unrestricted transitory dynamic effects are specified as $\Phi(\mathrm{L}) \zeta_{\mathrm{t}}$ in an augmented version of (19)

$$
\mathrm{AX}_{\mathrm{t}}=\zeta_{\mathrm{t}}+\Phi(\mathrm{L}) \zeta_{\mathrm{t}}=[\mathrm{I}+\Phi(\mathrm{L})] \zeta_{\mathrm{t}}
$$

where $\mathrm{I}$ is the $\mathrm{N} \times \mathrm{N}$ identity matrix and $\mathrm{I}+\Phi(\mathrm{L})$ is assumed invertible. Since the additional effects are transitory, the sum of coefficients in $\Phi(\mathrm{L}), \Phi(1)$, must equal zero. Values of these parameters have no effect on identification.

Each series in $\mathrm{X}$ appears difference stationary based on unit root tests. ${ }^{16}$ To model integrated data in a linear time series model, the structural disturbances must follow unit root processes

$$
\zeta_{\mathrm{t}}=\mathrm{d}+\zeta_{\mathrm{t}-1}+\varepsilon_{\mathrm{t}}
$$

where $d$ is the vector of drift terms and $\varepsilon_{t}$ is the vector of uncorrelated white noise innovations to the four structural disturbances. These uncorrelated innovations are referred to as structural shocks.

Taking the first difference of (20), premultiplying by the inverse of $\mathrm{I}+\Phi(\mathrm{L})$ and premultiplying by $\mathrm{A}^{-1}[\mathrm{I}+\Phi(0)]$ yields:

$$
\beta(\mathrm{L}) \Delta \mathrm{X}_{\mathrm{t}}=\omega+\mathrm{e}_{\mathrm{t}}
$$

where $\omega$ is a vector of constants. Hence, in the reduced form each variable is a function of lagged variables, a constant and a white noise error with 


$$
\beta(\mathrm{L})=\mathrm{A}^{-1}[\mathrm{I}+\Phi(0)][\mathrm{I}+\Phi(\mathrm{L})]^{-1} \mathrm{~A}, \mathrm{e}_{\mathrm{t}}=\mathrm{A}^{-1}[\mathrm{I}+\Phi(0)] \varepsilon_{\mathrm{t}} \text {, and } \omega=\mathrm{A}^{-1}[\mathrm{I}+\Phi(0)] \mathrm{d}
$$

Long-run structural parameters and the covariance matrix for structural shocks $\left(\Sigma_{\varepsilon}\right)$ are identified using the sum of the lag coefficients, $\beta(1)$, and the covariance matrix of the residuals, $\Sigma_{\mathrm{e}}$. From the definition of $\beta(\mathrm{L})$ and the assumption $\Phi(1)=0$, the sum of reduced-form coefficients is given by

$$
\beta(1)=\mathrm{A}^{-1}[\mathrm{I}+\Phi(0)] \mathrm{A} .
$$

The covariance matrix for residuals is a function of structural parameters:

$$
\Sigma_{\mathrm{e}}=\mathrm{A}^{-1}[\mathrm{I}+\Phi(0)] \Sigma_{\varepsilon}\left\{\mathrm{A}^{-1}[\mathrm{I}+\Phi(0)]\right\}^{\prime} .
$$

Using (23) to eliminate $\mathrm{I}+\Phi(0)$ from (24), and simplifying yields

$$
\beta(1)^{-1} \Sigma_{e}\left\{\beta(1)^{-1}\right\}^{\prime}=A^{-1} \Sigma_{\varepsilon}\left\{A^{-1}\right\}^{\prime} .
$$

This moment condition is used to estimate the long-run parameters and the covariance matrix of the structural shocks for a just-identified structural system. The full dynamic responses for the structural model are then obtained by combining these estimates and the reduced-form coefficients.

As is common in the structural VAR literature, the structural shocks are assumed uncorrelated. This assumption allows a unique variance decomposition to obtain. Furthermore, the parameters in A are unidentifiable using standard structural VAR methods if $\Sigma_{\varepsilon}$ is unconstrained. One last restriction is required to make the number of estimated parameters in (25), including shock standard errors, equal to the number of unique moments on the left side of this equation (in general $\mathrm{N}(\mathrm{N}+1) / 2$, in this case 10 ). Results are reported based on the assumption that the elasticity of savings with respect to output, $\mathrm{g}_{\mathrm{y}}$, is equal to one. If $\mathrm{g}_{\mathrm{y}}=1$, then $\alpha_{1}=0$ and the structure is recursive in the long run. This value seems most plausible given that the savings rate does not seem to vary as a country's output level increases. Nevertheless, results for money supply and money demand shocks are unaffected by the value of $\mathrm{g}_{\mathrm{y}}$ because the long-run structure is block recursive with recursive equations in the money market block. ${ }^{17}$ 


\section{Empirical Results}

Quarterly US data from 1959 to 1992 are used to estimate the models. The variables include the three-month Treasury bill interest rate, real GDP, M1 and M1 divided by the GDP deflator. It is easy to estimate all $4096\left(8^{4}\right)$ different AVAR specifications with 4 variables and up to 8 lags. The Akaike Information Criterion (AIC) and the Schwartz Information Criterion (SIC) are used to select AVAR specifications. ${ }^{18}$ The AIC chose a model with 5 lags of $\Delta \mathrm{R}, 2$ lags of $\Delta \mathrm{y}, 5$ lags of $\Delta \mathrm{m}$ and 4 lags of $\Delta \mathrm{M}$. The SIC chose the model with two lags for $\Delta \mathrm{m}$ and 1 lag for the other three variables. A VAR specification with 7 lags is selected using the modified likelihood ratio tests of Sims (1980).

Both AVARs find a higher percentage of significant reduced-form coefficients than the VAR. For example, the total number of parameters in the AIC model is a little more than half the number in the VAR, while both specifications find roughly the same number of parameters significant at the 5 percent level. Reduced-form coefficients are not reported..$^{19}$ Instead, attention is focused on structural parameters, impulse responses and variance decompositions to compare and contrast AVAR and VAR models.

\subsection{Long-run Structural Parameter Estimates}

Table 1 reports long-run structural parameter estimates along with standard errors. Standard errors are obtained using a bootstrap procedure. For each empirical model, 1000 replications of the model are constructed by drawing with replacement from the residuals. Long-run structural parameters are obtained from each replication using the same procedure that generates point estimates. Then the standard error for each long-run parameter is calculated from the 1000 replications. These same bootstrap replications are used to conduct statistical inference with the impulse responses and the variance decompositions.

Qualitatively similar estimates are obtained with all three models. Estimates for the interest rate 
semi-elasticities of aggregate supply and of money demand and the output elasticity of money supply are negative. Positive estimates are obtained for the income elasticity of money demand, the interest rate semielasticity of money supply and the elasticity of money supply to real balances.

These results permit conventional structural interpretations of each equation. The money supply parameters imply that the central bank (i.e. the Fed) tries to mitigate interest rate fluctuations, accommodate changes in the quantity of real balances and stabilize output movements. The money demand parameter estimates take on reasonable values. A negative coefficient on the interest rate in each modified aggregate supply equation suggests that the adverse effect of interest rates on the demand for capital is stronger than the positive effect interest rates may have on labor supply.

Every coefficient is statistically significant in at least one model, except for the semi-elasticity of aggregate supply with respect to the interest rate. For the VAR, the interest rate semi-elasticity of money demand and three structural shock standard errors are significant at the 1 percent level and the income and real balance elasticities for money supply are significant at the 10 percent level. All parameters significant at any level in the VAR are statistically significant at the 1 percent level in the AIC specification. The IS shock standard error also becomes significant at the 1 percent level in this AVAR model. Every significant parameter in the AIC specification is also significant in the SIC model at the same significance level. In addition, the income elasticity of money demand is significant at the 1 percent level and the interest rate semi-elasticity of money supply is significant at the 10 percent level.

For each parameter estimate, the SIC model's standard error is smaller than the corresponding standard error for the VAR. Standard errors are smaller in the AIC model than in the VAR, except for the parameters in the money demand function. The standard error from the SIC specification is smaller than that obtained in the AIC model for every parameter except for $\sigma_{\text {as }}$. 


\subsection{Impulse Responses}

Figures 1 through 8 (found in the Appendix) plot impulse responses. Each figure uses three solid lines to illustrate VAR results. For each triplet, the center line is the point estimate. The upper and lower lines enclose 90 percent confidence bounds. Using the same configuration, three dashed lines represent the results from an AVAR model. Confidence bounds are constructed from 1000 bootstrap replications of each model. The bootstrap responses of each variable to each shock are ordered from smallest to largest. The 50-th and the 950-th responses from this ordered set are the lower and upper bounds for the 90 percent confidence region.

Figures 1 through 4 plot the impulse responses and confidence regions for the SIC and VAR models. Figures 5 through 8 plot AIC and VAR results. These plots allow a convenient visual comparison of point estimates and the uncertainty associated with these estimates. Confidence regions for the SIC specification are generally narrower than confidence bounds for the VAR, although a few exceptions to this rule do exist. In fact, the SIC model's confidence regions are usually narrowest of all. The VAR model's confidence bounds are usually wider than the AIC model's bounds as can be seen, for example, in the responses to money supply shocks in Figure 5. However, there are examples where the VAR model yields modestly narrower bounds than the AIC model. Portions of the responses of real and nominal money to the other three shocks have their widest confidence intervals in the AIC model. Larger standard errors on parameters in the AIC model's long-run money demand function are the primary cause of this result.

Table 2 conveniently summarizes the impulse response results. Virtually all impulse responses correspond with the predicted effects of structural shocks. The long-run effect of a shock on a variable is obtained directly from the long-run structural parameters. Short-run and intermediate-run effects are jointly determined by reduced-form coefficients and long-run parameters.

The aggregate supply shock has a positive effect on output and a negative effect on the price level. 
Both effects are statistically significant in each model. Real balances increase following a supply shock in each model. As the number of reduced-form parameters decreases the portion of this real balance response that is statistically significant increases. This is typically the case, although the opposite effect of model size on the amount of an impulse response that is significant is sometimes observed. Interest rate responses to a supply shock serve as one example of this less common finding. While this response is initially negative in all cases ${ }^{20}$ the only model in which this negative effect is never significant is the SIC model.

The aggregate supply shock causes a drop in money for the VAR and AIC models, and these responses are initially significant. In contrast, money rises following a supply shock for the SIC specification and this response is initially significant. These responses provide the only examples where models obtain qualitatively different results that are statistically significant. These differences are associated with different parameter estimates for the short-run money supply function. If reasonable ranges for these parameter values were known, these different estimates could be used to possibly reject one or more of the empirical models. Unfortunately, theory is ambivalent about even the sign of these money supply parameters. If money supply is primarily driven by policy in the short run then money might decline following a beneficial supply shock if the Fed is trying to stabilize output fluctuations. On the other hand, if money supply in the short-run is primarily affected by commercial banks then a beneficial supply shock might induce banks to make more loans causing money supply to increase.

An IS shock results in a permanent increase in the interest rate and a significant rise in output for about one year. Because the estimated long-run interest rate semi-elasticity of aggregate supply is negative in all cases, output responses eventually become negative. Estimates of this long-run parameter are not statistically significant and therefore the negative portions of output's response to an IS shock are also insignificant. The other variables respond gradually to the IS shock. Real and nominal money balances eventually decline and the price level rises. Real money responses are sometimes significant for each empirical model while the money and price responses are occasionally significant for the VAR. 
The money supply shock causes a significant increase in money and the price level. Output temporarily rises and a portion of this response is significant in each model. Real balances temporarily rise, although this effect is only significant for the SIC specification. The interest rate initially falls in each case, but this effect is only significant for the AVARs. These interest rate responses reflect a liquidity effect. This response is then temporarily positive for the AIC and VAR specifications. This positive effect is only significant in the AIC specification, and may be explained by the fact that the nominal rate mixes real interest rate and expected inflation responses. If the liquidity effect is initially strongest but short-lived and the expected inflation effect gradually becomes more important, (perhaps due to recognition lags that might be a consequence of sticky price adjustment) then the nominal interest rate could respond to money supply shocks as observed here.

The money demand shock causes a decline in the price level that is initially significant and a significant increase in nominal and real money balances in each model. The output and interest rate responses to money demand from the two AVAR models are fundamentally different from these responses in the VAR. In each AVAR, both variables initially fall while in the VAR both variables initially rise, but only the initial decline of output in the SIC model is statistically significant. Hence, each empirical specification has some inconsistency with established theory which predicts a positive shock to money demand will raise the interest rate and lower output. However, if a money demand shock causes a decline in expected future inflation that exceeds the increase in the real interest rate, the nominal interest rate could initially fall as observed in both AVAR models. On the other hand, the rise in output for the VAR is more difficult to justify. This is the only example in which one model yields a theoretically implausible impulse response, although this result is statistically insignificant. These output responses to money demand suggest that a parsimonious AVAR specification may uncover structural effects that are difficult to discern with an overparameterized VAR. 


\subsection{Variance Decompositions}

Tables 3 through 6 present variance decompositions. Each table reports the variance of each variable explained by a particular structural shock from all three models. The identification method imposes restrictions on the long-run effects of shocks. For example, the only shock that has a permanent effect on the interest rate is the IS shock, and this causes the interest rate variance explained by the IS shock to asymptotically converge to 100 percent. Aggregate supply and IS shocks may have permanent effects on output. The money demand restrictions imply that the money supply shock (which permanently raises the level of money not its growth rate) is the only disturbance that can not have a long-run effect on real balances. Each shock may have a long-run effect money and the price level.

Standard errors for each variance decomposition are calculated using the same bootstrap procedure used with long-run structural parameters. These standard errors are typically smallest for the SIC model and largest for the VAR model, with standard errors from the AIC specification usually falling somewhere in between. ${ }^{21}$ Some exceptions to this tendency can, however, be found. Whenever the AIC model's standard error exceeds the VAR's standard error by more than 1 percentage point, the variance explained in the AIC model is substantially larger. Examples of this result are found for real money in Table 5 and for nominal money in Table 6. Similarly, when variance explained by the SIC model is relatively large, its standard error will occasionally exceed that from the other two specifications. See, for example, results for real balances in Table 4 and for output in Table 5.

Point estimates of variance exhibit interesting differences across the three models. This variation, particularly at longer horizons resembles the differences in long-run structural parameter estimates. For example, the SIC model has an interest rate semi-elasticity of money demand that is smallest in absolute value and has the least variance for real money balances explained by the IS shock. The aggregate supply shock explains the most variance of real balances in the SIC model at longer horizons and this model has 
the largest long-run elasticity of money demand to output. For shorter horizons, variance decompositions are jointly determined by the long-run parameter estimates and by the coefficients from the reduced form. The variance decomposition estimates from the AIC and VAR models are generally closer to each other than to the comparable estimate from the SIC model.

If $\mathrm{t}$ statistics are calculated, one finds larger $\mathrm{t}$ ratios for variance decompositions associated with statistically significant impulse responses. Of course, this result is not surprising because variance decompositions and impulse responses provide alternative means of characterizing system dynamics.

\section{Concluding Comments}

The SIC model's estimates are sometimes quite different than the other two models, and the SIC model's standard errors are typically the smallest. These findings suggest two alternative explanations: (1) the additional dynamic restrictions in the SIC specification are valid and structural parameters are estimated with greater precision; or (2) the SIC model imposes too many constraints on reduced-form dynamics and therefore obtains inconsistent structural parameter estimates. Evidence that only the SIC model's residuals are serially correlated supports the second explanation. ${ }^{22}$ Thus the quantitatively similar results from the other two models are used to address structural issues. ${ }^{23}$

The macroeconomic results from the VAR and the AIC models support and extend other research. A positive shock to money supply causes a liquidity effect as the nominal interest rate falls initially (Bernanke and Mihov 1998, Christiano, Eichenbaum and Evans 1996, Leeper and Gordon 1994, and Strongin 1995), ${ }^{24}$ and output's response to a money supply shock is hump-shaped (Cochrane 1998). However, only a modest amount of output variance is attributed to money supply shocks. Money demand shocks explain little of the variance of output or the interest rate. This finding can be explained by the

Fed's tendency to control interest rate fluctuations. ${ }^{25}$ Blanchard and Quah (1989) and others have found 
that aggregate demand shocks are an important source of business cycles. Our variance decompositions indicate that IS shocks are the most important aggregate demand factor for output. An interesting feature of the model in this paper is that IS shocks are allowed to potentially have a permanent effect on the level of output. However, this long-run effect is small and statistically insignificant. This finding is important because it provides empirical support for the identifying assumption used by Blanchard and Quah (1989), Shapiro and Watson (1988) and many others ${ }^{26}$ that aggregate supply is the sole source of permanent shocks to output.

The paper shows that AVAR models maintain the advantages associated with VAR models. Both types of models are linear reduced forms of an underlying structure, and both are consistently and efficiently estimated by OLS. However, AVAR models permit a more flexible multivariate dynamic specification which may yield more efficient estimates. Hence, the AVAR approach provides a constructive response to some of the inference problems with VARs noted by Runkle (1987) and others.

A number of potentially important questions about AVAR modeling are still unexplored. Will AVARs yield superior forecasts? If economic dynamics are modeled by AVAR models will that affect Granger causality test results? Can empirical models be improved by combining the AVAR approach with other methods that have been developed to constrain the coefficients in a VAR? These and other questions about AVAR modeling remain as topics for future study. 
Table 1 :

Long-run Structural Parameter Estimates

\begin{tabular}{|c|c|c|c|}
\hline Parameter & $\begin{array}{l}\text { VAR } \\
\text { Model }\end{array}$ & $\begin{array}{c}\text { AIC } \\
\text { Model }\end{array}$ & $\begin{array}{c}\text { SIC } \\
\text { Model }\end{array}$ \\
\hline " 2 & $\begin{array}{l}-0.8335 \\
(0.8618)\end{array}$ & $\begin{array}{l}-0.4293 \\
(0.6500)\end{array}$ & $\begin{array}{l}-0.0867 \\
(0.4379)\end{array}$ \\
\hline$d_{R}$ & $\begin{array}{l}-3.0371 \\
(0.8823)\end{array}$ & $\begin{array}{l}-2.7688 \\
(0.9950)\end{array}$ & $\begin{array}{l}-1.5519 \text { * } \\
(0.4411)\end{array}$ \\
\hline$d_{y}$ & $\begin{array}{c}0.6937 \\
(0.4697)\end{array}$ & $\begin{array}{c}0.6642 \\
(0.6068)\end{array}$ & $\begin{array}{l}1.1188 \text { * } \\
(0.2982)\end{array}$ \\
\hline$f_{R}$ & $\begin{array}{c}1.3298 \\
(1.3793)\end{array}$ & $\begin{array}{c}0.7891 \\
(0.7279)\end{array}$ & $\begin{array}{c}0.5239+ \\
(0.2831)\end{array}$ \\
\hline$f_{y}$ & $\begin{array}{c}-1.2252+ \\
(0.7073)\end{array}$ & $\begin{array}{l}-1.3214 * * \\
(0.4164)\end{array}$ & $\begin{array}{l}-0.7378 \text { * } \\
(0.2254)\end{array}$ \\
\hline$f_{m}$ & $\begin{array}{c}0.7749 \\
(0.4504)\end{array}+$ & $\begin{array}{l}0.7885 \\
(0.2664)\end{array}$ & $\begin{array}{l}0.8258 \\
(0.1590)\end{array}$ * \\
\hline $\mathrm{F}_{\text {is }}$ & $\begin{array}{c}0.0064 \\
(0.0052)\end{array}$ & $\begin{array}{l}0.0066 \\
(0.0020)\end{array}$ & $\begin{array}{l}0.0092 \text { * } \\
(0.0017)\end{array}$ \\
\hline $\mathrm{F}_{\text {as }}$ & $\begin{array}{l}0.0104 \\
(0.0032)\end{array}$ & $\begin{array}{l}0.0116 \\
(0.0027)\end{array}$ & $\begin{array}{l}0.0153 \\
(0.0031)\end{array}$ \\
\hline $\mathrm{F}_{\mathrm{md}}$ & $\begin{array}{l}0.0126 \\
(0.0028)\end{array}$ & $\begin{array}{l}0.0183 \\
(0.0050)\end{array}$ & $\begin{array}{l}0.0161 \text { * } \\
(0.0026)\end{array}$ \\
\hline $\mathrm{F}_{\mathrm{ms}}$ & $\begin{array}{l}0.0149 \\
(0.0041)\end{array}$ & $\begin{array}{l}0.0126 \\
(0.0026)\end{array}$ & $\begin{array}{l}0.0107 \text { * } \\
(0.0017)\end{array}$ \\
\hline
\end{tabular}

Significant estimates at $10 \%(+)$ and $1 \%(* *)$ levels are marked accordingly. Standard errors are in parentheses. 
Table 2:

Summary of Impulse Response Functions

\begin{tabular}{|c|c|c|c|c|c|c|c|c|c|c|c|c|c|}
\hline \multirow[b]{2}{*}{ Variable } & \multirow{2}{*}{$\begin{array}{l}\text { Quarter (s) } \\
\text { Ahead }\end{array}$} & \multicolumn{3}{|c|}{$\begin{array}{l}\text { Aggregate } \\
\text { Supply } \\
\text { Shock }\end{array}$} & \multicolumn{3}{|c|}{$\begin{array}{c}\text { IS } \\
\text { Shock }\end{array}$} & \multicolumn{3}{|c|}{$\begin{array}{l}\text { Money } \\
\text { Demand } \\
\text { Shock }\end{array}$} & \multicolumn{3}{|c|}{$\begin{array}{l}\text { Money } \\
\text { Supply } \\
\text { Shock }\end{array}$} \\
\hline & & $\mathrm{V}$ & $\mathrm{A}$ & S & $\mathrm{V}$ & A & S & $\mathrm{V}$ & A & S & $\mathrm{V}$ & A & S \\
\hline \multirow[t]{6}{*}{ Output } & 1 & $+*$ & $+*$ & $+*$ & $+*$ & $+*$ & $+\star$ & + & 0 & $-\star$ & + & $+*$ & + \\
\hline & 2 & $+\star$ & $+\star$ & $+*$ & $+\star$ & $+*$ & $+\star$ & + & - & $-\star$ & + & + & + \\
\hline & 4 & $+*$ & $+*$ & $+*$ & $+*$ & $+*$ & $+*$ & + & + & $-\star$ & $+*$ & $+*$ & $+*$ \\
\hline & 8 & $+*$ & $+*$ & $+*$ & - & 0 & + & - & - & - & + & + & $+*$ \\
\hline & 16 & $+*$ & $+*$ & $+*$ & - & - & 0 & - & 0 & 0 & + & + & + \\
\hline & 32 & $+*$ & $+*$ & $+*$ & - & - & - & 0 & 0 & 0 & + & 0 & 0 \\
\hline Interest & 1 & - & $-\star$ & - & $+*$ & $+*$ & $+\star$ & + & - & - & - & $-\star$ & $-\star$ \\
\hline \multirow[t]{5}{*}{ Rate } & 2 & - & $-\star$ & + & $+*$ & $+*$ & $+*$ & + & - & - & - & - & - \\
\hline & 4 & $-\star$ & - & + & $+\star$ & $+*$ & $+\star$ & + & + & - & + & $+\star$ & - \\
\hline & 8 & - & - & 0 & $+*$ & $+*$ & $+*$ & + & - & 0 & + & $+*$ & 0 \\
\hline & 16 & + & - & 0 & $+*$ & $+*$ & $+\star$ & - & 0 & 0 & + & + & 0 \\
\hline & 32 & 0 & 0 & 0 & $+\star$ & $+*$ & $+\star$ & 0 & 0 & 0 & 0 & 0 & 0 \\
\hline Real & 1 & 0 & 0 & $+*$ & 0 & 0 & 0 & $+\star$ & $+\star$ & $+*$ & 0 & + & + \\
\hline \multirow[t]{5}{*}{ Balances } & 2 & 0 & + & $+*$ & $-\star$ & - & - & $+\star$ & $+\star$ & $+*$ & + & + & $+*$ \\
\hline & 4 & + & $+*$ & $+*$ & $-\star$ & - & $-\star$ & $+*$ & $+\star$ & $+\star$ & 0 & + & + \\
\hline & 8 & + & + & $+\star$ & $-\star$ & $-\star$ & $-\star$ & $+\star$ & $+\star$ & $+\star$ & + & + & + \\
\hline & 16 & + & + & $+*$ & $-\star$ & $-\star$ & $-\star$ & $+\star$ & $+\star$ & $+*$ & 0 & 0 & 0 \\
\hline & 32 & + & + & $+\star$ & $-\star$ & $-\star$ & - & $+*$ & $+*$ & $+\star$ & 0 & 0 & 0 \\
\hline \multirow[t]{6}{*}{ Money } & 1 & $-\star$ & $-\star$ & $+*$ & 0 & 0 & + & $+\star$ & $+\star$ & $+*$ & + & $+*$ & $+*$ \\
\hline & 2 & $-\star$ & - & + & - & - & 0 & $+\star$ & $+\star$ & $+\star$ & + & $+\star$ & $+\star$ \\
\hline & 4 & - & - & + & $-\star$ & - & - & $+\star$ & $+\star$ & $+\star$ & + & $+\star$ & $+\star$ \\
\hline & 8 & - & - & + & $-\star$ & - & - & $+\star$ & $+\star$ & $+\star$ & + & $+\star$ & $+*$ \\
\hline & 16 & - & - & + & - & - & - & $+\star$ & $+\star$ & $+\star$ & $+\star$ & $+\star$ & $+\star$ \\
\hline & 32 & - & - & + & - & - & - & $+\star$ & $+\star$ & $+\star$ & $+\star$ & $+*$ & $+\star$ \\
\hline \multirow[t]{6}{*}{ Price } & 1 & $-\star$ & $-\star$ & $-\star$ & 0 & 0 & 0 & $-\star$ & $-\star$ & $-\star$ & $+\star$ & $+*$ & $+\star$ \\
\hline & 2 & $-\star$ & $-\star$ & $-\star$ & + & + & + & - & $-\star$ & - & $+\star$ & $+\star$ & $+\star$ \\
\hline & 4 & $-\star$ & $-\star$ & $-\star$ & + & + & + & - & - & - & $+*$ & $+\star$ & $+\star$ \\
\hline & 8 & $-\star$ & $-\star$ & $-\star$ & $+*$ & + & + & - & - & - & $+\star$ & $+*$ & $+\star$ \\
\hline & 16 & $-\star$ & $-\star$ & $-\star$ & + & + & + & - & - & - & $+\star$ & $+*$ & $+*$ \\
\hline & 32 & $-\star$ & $-\star$ & $-\star$ & + & + & + & - & - & - & $+*$ & $+\star$ & $+\star$ \\
\hline
\end{tabular}

This table indicates if the response of a variable to a shock is positive (+), negative (-) or virtually zero (0) in the $\operatorname{VAR}(\mathrm{V})$, the AIC (A) or the SIC (S) model. An asterisk indicates if essentially all the 90 percent confidence region is on the same side of zero as the point estimate. 
Table 3:

Percentage of Variance Explained by IS Shocks

\begin{tabular}{|c|c|c|c|c|c|c|c|}
\hline \multirow{2}{*}{$\frac{\text { Variable }}{\text { Output }}$} & Quarter (s) & \multicolumn{2}{|c|}{ VAR } & \multicolumn{2}{|c|}{ AIC } & \multicolumn{2}{|c|}{ SIC } \\
\hline & 1 & 42 & (19) & 55 & (12) & 22 & $(10)$ \\
\hline & 2 & 53 & (19) & 63 & (13) & 22 & $(10)$ \\
\hline & 4 & 44 & (18) & 51 & (12) & 17 & (11) \\
\hline & 8 & 21 & (11) & 29 & $(10)$ & 8 & (9) \\
\hline & 16 & 15 & $(10)$ & 15 & $(8)$ & 3 & $(8)$ \\
\hline & 32 & 14 & (13) & 9 & (11) & 2 & $(8)$ \\
\hline & 48 & 15 & (15) & 8 & (12) & 1 & ( 8) \\
\hline Interest & 1 & 75 & $(22)$ & 73 & $(16)$ & 86 & $(14)$ \\
\hline Rate & 2 & 83 & $(20)$ & 80 & (15) & 92 & (11) \\
\hline & 4 & 86 & (18) & 83 & (16) & 95 & $(7)$ \\
\hline & 8 & 92 & (17) & 90 & (15) & 97 & ( 4$)$ \\
\hline & 16 & 94 & (14) & 93 & (11) & 99 & ( 2) \\
\hline & 32 & 96 & (11) & 96 & $(8)$ & 99 & $(1)$ \\
\hline & 48 & 98 & $(9)$ & 97 & $(6)$ & 100 & $(1)$ \\
\hline Real & 1 & 4 & $(8)$ & 1 & (10) & 6 & (13) \\
\hline Balances & 2 & 20 & (13) & 5 & $(8)$ & 7 & $(5)$ \\
\hline & 4 & 37 & (18) & 14 & (13) & 15 & $(10)$ \\
\hline & 8 & 60 & $(21)$ & 35 & (19) & 23 & (14) \\
\hline & 16 & 68 & $(22)$ & 46 & $(22)$ & 27 & $(16)$ \\
\hline & 32 & 70 & $(22)$ & 49 & (23) & 28 & $(17)$ \\
\hline & 48 & 71 & $(22)$ & 50 & (23) & 29 & (18) \\
\hline Money & 1 & 0 & $(8)$ & 3 & (14) & 16 & (13) \\
\hline & 2 & 6 & $(10)$ & 2 & $(10)$ & 4 & $(6)$ \\
\hline & 4 & 18 & (15) & 6 & (12) & 5 & ( 5) \\
\hline & 8 & 37 & $(20)$ & 17 & (17) & 9 & $(8)$ \\
\hline & 16 & 37 & $(22)$ & 20 & (19) & 12 & (11) \\
\hline & 32 & 25 & $(20)$ & 16 & (19) & 13 & (12) \\
\hline & 48 & 18 & $(20)$ & 14 & (19) & 14 & (13) \\
\hline Price & 1 & 13 & $(16)$ & 2 & (11) & 4 & $(10)$ \\
\hline & 2 & 18 & (18) & 5 & (12) & 9 & (13) \\
\hline & 4 & 24 & $(20)$ & 9 & (15) & 11 & (14) \\
\hline & 8 & 37 & (23) & 17 & (18) & 13 & (15) \\
\hline & 16 & 45 & $(25)$ & 24 & (21) & 15 & $(16)$ \\
\hline & 32 & 46 & $(26)$ & 26 & (23) & 16 & $(16)$ \\
\hline & 48 & 47 & $(27)$ & 27 & (23) & 16 & (16) \\
\hline
\end{tabular}

Standard errors are in parentheses. 
Table 4:

Percentage of Variance Explained by Aggregate Supply Shocks

\begin{tabular}{|c|c|c|c|c|c|c|c|}
\hline \multirow{2}{*}{$\frac{\text { Variable }}{\text { Output }}$} & \multicolumn{3}{|c|}{ Quarter (s) } & \multicolumn{2}{|c|}{ AIC } & \multicolumn{2}{|c|}{ SIC } \\
\hline & 1 & 35 & $(22)$ & 27 & $(18)$ & 48 & (17) \\
\hline & 2 & 30 & $(21)$ & 23 & $(17)$ & 53 & (16) \\
\hline & 4 & 32 & $(21)$ & 27 & $(18)$ & 67 & (13) \\
\hline & 8 & 55 & $(18)$ & 52 & (15) & 83 & (9) \\
\hline & 16 & 69 & (15) & 76 & (9) & 93 & ( 8) \\
\hline & 32 & 78 & (15) & 87 & $(11)$ & 97 & ( 8) \\
\hline & 48 & 79 & (16) & 90 & (12) & 98 & $(8)$ \\
\hline Interest & 1 & 3 & (14) & 8 & (15) & 1 & ( 8) \\
\hline Rate & 2 & 3 & (14) & 9 & (14) & 1 & ( 5) \\
\hline & 4 & 6 & (14) & 8 & $(12)$ & 0 & ( 4) \\
\hline & 8 & 4 & (12) & 6 & $(11)$ & 0 & ( 2) \\
\hline & 16 & 3 & $(10)$ & 4 & $(8)$ & 0 & ( 1) \\
\hline & 32 & 2 & $(7)$ & 2 & ( 5) & 0 & ( 1) \\
\hline & 48 & 1 & $(6)$ & 2 & (4) & 0 & $(0)$ \\
\hline Real & 1 & 0 & $(7)$ & 1 & $(8)$ & 40 & (15) \\
\hline Balances & 2 & 0 & $(7)$ & 2 & $(10)$ & 39 & (15) \\
\hline & 4 & 1 & $(8)$ & 4 & $(12)$ & 35 & (15) \\
\hline & 8 & 6 & (12) & 8 & $(14)$ & 34 & (15) \\
\hline & 16 & 7 & (13) & 8 & (13) & 35 & (15) \\
\hline & 32 & 7 & (12) & 8 & (13) & 37 & (16) \\
\hline & 48 & 7 & $(12)$ & 8 & $(13)$ & 37 & (16) \\
\hline Money & 1 & 21 & (15) & 14 & $(14)$ & 5 & ( 7) \\
\hline & 2 & 18 & (14) & 9 & $(11)$ & 3 & ( 7) \\
\hline & 4 & 11 & (12) & 5 & (9) & 2 & ( 6) \\
\hline & 8 & 4 & (9) & 4 & (9) & 1 & $(6)$ \\
\hline & 16 & 3 & (9) & 6 & (11) & 2 & ( 7) \\
\hline & 32 & 5 & (12) & 11 & (13) & 2 & ( 8) \\
\hline & 48 & 7 & (13) & 13 & (14) & 2 & ( 8) \\
\hline Price & 1 & 53 & $(23)$ & 56 & (19) & 55 & (15) \\
\hline & 2 & 56 & (23) & 59 & (19) & 53 & (15) \\
\hline & 4 & 54 & (23) & 60 & (19) & 52 & (15) \\
\hline & 8 & 46 & $(22)$ & 56 & (19) & 52 & (16) \\
\hline & 16 & 35 & $(22)$ & 50 & $(20)$ & 52 & (16) \\
\hline & 32 & 29 & $(22)$ & 47 & $(20)$ & 52 & (16) \\
\hline & 48 & 27 & $(22)$ & 46 & $(20)$ & 52 & (17) \\
\hline
\end{tabular}

Standard errors are in parentheses. 
Table 5:

Percentage of Variance Explained by Money Demand Shocks

\begin{tabular}{|c|c|c|c|c|c|c|c|}
\hline \multirow{2}{*}{$\frac{\text { Variable }}{\text { Output }}$} & \multicolumn{3}{|c|}{ Quarter (s) } & \multicolumn{2}{|c|}{$\mathrm{AIC}$} & \multicolumn{2}{|c|}{ SIC } \\
\hline & 1 & 5 & $(10)$ & & $(9)$ & 23 & (13) \\
\hline & 2 & & $(8)$ & & $(8)$ & 19 & (11) \\
\hline & 4 & & $(9)$ & 0 & $(7)$ & 12 & $(7)$ \\
\hline & 8 & 2 & ( 6) & 1 & ( 5) & 6 & $(3)$ \\
\hline & 16 & & ( 5) & 0 & ( 3$)$ & 2 & $(1)$ \\
\hline & 32 & & $(3)$ & 0 & $(1)$ & 1 & $(1)$ \\
\hline & 48 & & $(2)$ & 0 & ( 1 ) & 1 & $(0)$ \\
\hline Interest & 1 & 0 & $(8)$ & & $(9)$ & 2 & $(6)$ \\
\hline Rate & 2 & 0 & $(8)$ & 1 & $(9)$ & 1 & $(5)$ \\
\hline & 4 & & $(6)$ & 1 & $(7)$ & 1 & $(3)$ \\
\hline & 8 & 1 & ( 5) & 1 & ( 5) & 0 & $(2)$ \\
\hline & 16 & & ( 4) & 0 & ( 4) & 0 & $(1)$ \\
\hline & 32 & & $(3)$ & 0 & $(2)$ & 0 & $(1)$ \\
\hline & 48 & 0 & $(2)$ & 0 & $(2)$ & 0 & $(0)$ \\
\hline Real & 1 & 95 & $(16)$ & 97 & $(16)$ & 54 & $(16)$ \\
\hline Balances & 2 & 79 & (18) & 86 & (17) & 50 & (15) \\
\hline & 4 & 61 & $(20)$ & 74 & (19) & 47 & (15) \\
\hline & 8 & 34 & (19) & 55 & $(20)$ & 42 & $(16)$ \\
\hline & 16 & 25 & (18) & 46 & $(21)$ & 37 & (16) \\
\hline & 32 & 23 & (18) & 43 & $(21)$ & 35 & $(17)$ \\
\hline & 48 & 22 & $(18)$ & 43 & (21) & 34 & (17) \\
\hline Money & 1 & 74 & $(21)$ & 65 & $(21)$ & 53 & $(16)$ \\
\hline & 2 & 66 & $(21)$ & 59 & $(20)$ & 50 & (14) \\
\hline & 4 & 62 & $(21)$ & 59 & $(21)$ & 50 & $(14)$ \\
\hline & 8 & 49 & $(20)$ & 54 & $(20)$ & 50 & $(14)$ \\
\hline & 16 & 43 & (19) & 51 & (19) & 50 & $(14)$ \\
\hline & 32 & 38 & (18) & 47 & (18) & 50 & $(14)$ \\
\hline & 48 & 35 & (18) & 45 & $(18)$ & 50 & $(14)$ \\
\hline Price & 1 & 13 & $(17)$ & 20 & (17) & 2 & \\
\hline & 2 & 8 & (14) & 15 & (15) & 1 & $(5)$ \\
\hline & 4 & 4 & (11) & 9 & (13) & 1 & ( 5) \\
\hline & 8 & 1 & $(8)$ & 5 & $(10)$ & 1 & $(4)$ \\
\hline & 16 & 0 & $(7)$ & 3 & $(8)$ & 2 & (4) \\
\hline & 32 & 1 & $(8)$ & 3 & $(8)$ & 2 & $(5)$ \\
\hline & 48 & 1 & $(8)$ & 3 & $(8)$ & 2 & ( 5) \\
\hline
\end{tabular}

Standard errors are in parentheses. 
Table 6:

Percentage of Variance Explained by Money Supply Shocks

\begin{tabular}{|c|c|c|c|c|c|c|c|}
\hline \multirow{2}{*}{$\frac{\text { Variable }}{\text { Output }}$} & \multicolumn{3}{|c|}{ Quarter (s) } & \multicolumn{2}{|c|}{$\mathrm{AIC}$} & \multicolumn{2}{|c|}{ SIC } \\
\hline & 1 & 18 & $(20)$ & 17 & (15) & 7 & $(8)$ \\
\hline & 2 & 14 & (18) & 14 & (14) & 5 & $(6)$ \\
\hline & 4 & 18 & (18) & 22 & (14) & 4 & (4) \\
\hline & 8 & 21 & (15) & 18 & $(10)$ & 2 & ( 2) \\
\hline & 16 & 14 & $(10)$ & 9 & (4) & 1 & $(1)$ \\
\hline & 32 & 8 & $(7)$ & 4 & $(2)$ & 0 & $(0)$ \\
\hline & 48 & 5 & ( 5) & 3 & ( 1$)$ & 0 & $(0)$ \\
\hline Interest & 1 & 22 & (19) & 19 & (16) & 12 & (11) \\
\hline Rate & 2 & 13 & (16) & 11 & (12) & 7 & ( 7) \\
\hline & 4 & 6 & $(10)$ & 8 & $(6)$ & 4 & $(4)$ \\
\hline & 8 & 3 & $(8)$ & 4 & ( 5) & 2 & $(2)$ \\
\hline & 16 & 2 & $(6)$ & 3 & (4) & 1 & ( 1$)$ \\
\hline & 32 & 1 & $(4)$ & 2 & $(2)$ & 1 & ( 1$)$ \\
\hline & 48 & 1 & ( 3$)$ & 1 & ( 2) & 0 & $(0)$ \\
\hline Real & 1 & 1 & (14) & 1 & (10) & 1 & ( 4) \\
\hline Balances & 2 & 1 & (12) & 7 & (13) & 4 & ( 5) \\
\hline & 4 & 1 & (11) & 7 & (12) & 4 & (4) \\
\hline & 8 & 0 & (9) & 3 & $(6)$ & 2 & $(2)$ \\
\hline & 16 & 0 & $(7)$ & 1 & (3) & 1 & ( 1$)$ \\
\hline & 32 & 0 & ( 4) & 0 & ( 1) & 0 & $(0)$ \\
\hline & 48 & 0 & ( 3$)$ & 0 & ( 1) & 0 & $(0)$ \\
\hline Money & 1 & 5 & $(16)$ & 19 & (19) & 27 & (14) \\
\hline & 2 & 10 & (18) & 30 & $(20)$ & 42 & (14) \\
\hline & 4 & 9 & (17) & 30 & $(20)$ & 43 & (13) \\
\hline & 8 & 10 & (15) & 25 & (18) & 40 & (13) \\
\hline & 16 & 17 & (16) & 23 & (17) & 37 & (12) \\
\hline & 32 & 31 & $(17)$ & 26 & (16) & 35 & (13) \\
\hline & 48 & 40 & (18) & 28 & (16) & 34 & (13) \\
\hline Price & 1 & 22 & $(22)$ & 22 & $(20)$ & 39 & (16) \\
\hline & 2 & 18 & $(21)$ & 21 & (19) & 36 & (15) \\
\hline & 4 & 18 & $(21)$ & 22 & (18) & 36 & (14) \\
\hline & 8 & 16 & (19) & 22 & (17) & 34 & (14) \\
\hline & 16 & 20 & (19) & 23 & (17) & 31 & (14) \\
\hline & 32 & 24 & (19) & 24 & (17) & 30 & (15) \\
\hline & 48 & 25 & (19) & 24 & (17) & 30 & (15) \\
\hline
\end{tabular}

Standard errors are in parentheses. 


\section{Notes}

1. Those who interpret VAR to mean "Very Awful Regression" would naturally concur. Many VAR advocates also accept some of Runkle's views. For example, see the comments on Runkle's paper by Blanchard, Sims and Watson.

2. Doan, Litterman and Sims (1984) extend the basic approach.

3. However, Ingram and Whiteman (1994) construct the prior based on a Real Business Cycle model.

4. Finite VARs are often criticized for failure to fit infinite order VAR processes. However, see Lutkepohl and Saikkonen (1997) on this issue.

5. Shapiro and Watson (1988) and Blanchard and Quah (1989) developed this approach. Gali (1992) combined short-run and long-run restrictions for identification purposes. King, Plosser, Stock and Watson (1991) present a method to identify permanent shocks in cointegrated time series.

6. Originally Sims (1980) used recursive contemporaneous models to identify VARs. Following Cooley and LeRoy (1985) and other criticisms, Bernanke (1986), Blanchard and Watson (1986) and Sims (1986) developed more general methods of imposing short-run restrictions in VAR models. Keating (1990) and West (1990) employed rational expectations to derive contemporaneous identification restrictions.

7. The constants that do matter are the drift terms in the unit root shock processes.

8. The identification restrictions would not be altered if labor supply is also a function of output.

9. International factors are not explicitly modeled. However, if net exports are a function of the real exchange rate and output and if the real exchange rate is a function of domestic and foreign real interest rates, the savings shock will be a function of international disturbances.

10. With $\rho_{t}$ the depreciation rate and $d_{t}$ the growth rate of capital

$$
I_{t}=d_{t} K_{t}+\rho_{t} K_{t} \text {, where } d_{t}=\frac{K_{t+1}-K_{t}}{K_{t}} \text {. }
$$

This implies, $\log \mathrm{I}_{\mathrm{t}}=\log \mathrm{K}_{\mathrm{t}}+\log \left(\mathrm{d}_{\mathrm{t}}+\rho_{\mathrm{t}}\right)$

11. Higher order terms are unimportant if $\Delta \mathrm{P}$ and $\mathrm{r}$ are small.

12. Unit root tests provide some evidence supporting this specification, although one can not definitively reject the hypothesis that inflation is difference stationary in postwar data.

13. If inflation and expected inflation did not share the same order of integration, they would diverge asymptotically. This would be inconsistent with rational expectations in its simplest form.

14. If inflation and real balances are difference stationary, then money growth must also be difference stationary. This set of alternative assumptions could easily be handled in this econometric model. However, Shapiro and Watson (1988) and others reject a unit root in M1 growth. 
15. The effects of each shock on each variable are not required to be identical or even proportional to one another. They simply must "differ up to a scalar lag polynomial" as is shown in the Appendix to Blanchard and Quah (1989). Also see Faust and Leeper (1997) for relevant analytical results.

16. For example, Schwert (1987) provides a battery of unit root diagnostics on related times series. Nelson and Plosser (1982) use comparable series over a longer span of time. These unit root results were confirmed for the data in this paper with augmented Dickey-Fuller tests.

17. Keating (1998) proves this result for a more general case. The empirical model was also estimated under the assumption that the real interest rate has no effect on aggregate supply and $\mathrm{g}_{\mathrm{y}}$ is unconstrained. The results for IS and aggregate supply shocks were very similar in the short run and at business cycle frequencies to the results in the paper. The only differences occur for long-run responses to the two real shocks, but these results are not statistically distinguishable from reported results.

18. It took a Pentium-based personal computer less than one hour to estimate all possible AVAR specifications and select optimal models.

19. These coefficients are available on request.

20. Prescott (1986) and others have shown that a beneficial aggregate supply shock causes a temporary rise in the real rate for the Real Business Cycle model. The nominal interest rate would fall if the drop in expected inflation exceeds the increase in the real interest rate.

21. The standard errors sometimes round to zero, particularly for some of the responses identified by longrun zero restrictions.

22. Based on Lagrange Multiplier tests, the AIC model's residuals do not exhibit any autocorrelation at the $10 \%$ level. On the other hand, the SIC specification has interest rate residuals that reject white noise at virtually any level of significance and real balances residuals that reject white noise at the 10 percent level.

23. Additional support for using the AIC comes from Ozcicek and McMillin (1998) who find that the AIC will choose the correct AVAR specification with much greater frequency than will the SIC in a Monte Carlo study of bivariate models.

24. McMillin (1998) compares and contrasts these models and a model based on long-run structural restrictions. His long-run identifying restrictions, however, are not the same as those used in this paper.

25. Poole (1970) was first to show that targeting interest rates would neutralize the effects of money demand shocks on interest rates and output.

26. A partial list includes Amed, Ickes, Wang and Yoo (1993), Bayoumi and Eichengreen (1994), Bordo (1993), Faust and Leeper (1997), Gamber and Joutz (1993), Karras (1994), Keating and Nye (1998), Keating and Nye (1999) and Lastrapes and Selgin (1995). However, Keating and Nye (1998) find evidence that permanent output shocks are associated with aggregate demand in many economies before World War I. 


\section{References}

Amed, Shagil, Barry W. Ickes, Ping Wang and Byong S. Yoo (1993) "International business cycles," American Economic Review, 83:335-359.

Bayoumi, Tamin and Barry Eichengreen (1994) "Macroeconomic adjustment under Bretton Woods and the post-Bretton Woods float: An impulse response analysis," The Economic Journal, 104: 813-827.

Bernanke, Ben S. (1986) "Alternative explanations of the money-income correlation," Real Business Cycles, Real Exchange Rates and Actual Policies, Carnegie-Rochester Conference Series, eds. K. Brunner and A.H. Meltzer, 25:49-100.

Bernanke, Ben and Ilian Mihov (1998) "Measuring monetary policy," forthcoming in Quarterly Journal of Economics.

Blanchard, Olivier J. and Danny Quah (1989) "The dynamic effects of aggregate demand and aggregate supply disturbances," American Economic Review, 79: 655-673.

Blanchard, Olivier J. and Mark W. Watson (1986) "Are business cycles all alike?," in The American Business Cycle: Continuity and Change, ed. R.J. Gordon, NBER, University of Chicago Press, 123-156.

Bordo, Michael D. (1993) "The gold standard, Bretton Woods and other monetary regimes: A historical appraisal," in Dimensions of Monetary Policy, Federal Reserve Bank of St. Louis, 123-191.

Christiano, Lawrence J., Martin Eichenbaum and Charles Evans (1996) The effects of monetary policy shocks: Evidence from the flow of funds, Review of Economics and Statistics 78, 16-34.

Cochrane, John H. (1998) "What do the VARs mean? Measuring the output effects of monetary policy," Journal of Monetary Economics 41, 277-300.

Cooley, Thomas A. and Stephen F. LeRoy (1985) "Atheoretical macroeconomics: A critique," Journal of Monetary Economics, 16:283-308.

Dickey, David A. and Wayne A. Fuller (1979) "Distribution of estimators for autoregressive time series with unit roots," Journal of the American Statistical Association, 77:427-31.

Doan, Thomas, Robert B. Litterman, and Christopher A. Sims (1984) "Forecasting and conditional projection using realistic prior distributions," Econometric Reviews 3:1-144.

Faust, John and Eric Leeper (1997) "When do long-run identifying restrictions give reliable results?," Journal of Business and Economic Statistics 15, 345-353.

Gali, Jordi (1992) "How well does the IS-LM model fit postwar U.S. data," Quarterly Journal of Economics, 57:709-38.

Gamber, Edward N. and Frederick L. Joutz (1993) "The dynamic effects of aggregate demand and supply disturbances: Comment," American Economic Review, 83: 1387-1393. 
Hsiao, Cheng (1981) "Autoregressive modeling and money-income causality detection," Journal of Monetary Economics, 7:85-106.

Ingram, Beth F. and Charles Whiteman (1994) "Supplanting the Minnesota prior: Forecasting macroeconomic times series using real business cycle model priors," Journal of Monetary Economics, 34:497-510.

Karras, George (1994) "Aggregate demand and supply shocks in Europe: 1860-1987," The Journal of European Economic History, 22:79-98.

Keating, John W. (1990) "Identifying VAR models under rational expectations," Journal of Monetary Economics, 25:453-476.

Keating, John W. (1998) "Structural inference with long-run recursive empirical models," University of Kansas Working Paper.

Keating, John W. and John V. Nye (1998) "Permanent and transitory shocks in real output: Estimates from nineteenth century and postwar economies," Journal of Money, Credit and Banking 30, 231-251.

Keating, John W. and John V. Nye (1999) "The dynamic effects of aggregate demand and supply disturbances in the G7 countries," forthcoming in Journal of Macroeconomics.

King, Robert G., Charles I. Plosser, James H. Stock and Mark W. Watson (1991) "Stochastic trends and economic fluctuations," American Economic Review, 81:819-840.

Lastrapes, William D. and George Selgin (1995) "The liquidity effect: Identifying short-run interest rate dynamics using long-run restrictions," Journal of Macroeconomics 17, 387-404.

Leeper, Eric M. and David B. Gordon (1994) The dynamic impacts of monetary policy: An exercise in tentative identification, Journal of Political Economy 102, 1228-1247.

Litterman, Robert B. (1986) "Forecasting with Bayesian vector autoregressions - Five years of experience," Journal of Business and Economic Statistics, 4:25-38.

Lutkepohl, Helmut and Pentti Saikkonen (1997) "Impulse response analysis in infinite order cointegrated vector autoregressive processes," Journal of Econometrics, 81:127-157

McMillin, W. Douglas (1998) "The effects of monetary policy shocks: Comparing contemporaneous and long-run identifying restrictions," working paper.

Nelson, Charles R. and Charles I. Plosser (1982) "Trends and random walks in macroeconomic time series: Some evidence and implications," Journal of Monetary Economics, 10:129-162.

Ozcicek, Omer and W. Douglas McMillin (1998) "Lag length selection in vector autoregressive models: Symmetric and asymmetric lags," forthcoming in Applied Economics.

Poole, William (1970) "Optimal choice of monetary policy instruments in a simple stochastic macro- 
model," Quarterly Journal of Economics, 84: 197-216.

Prescott, Edward C. (1986) "Theory ahead of business cycle measurement," Real Business Cycles, Real Exchange Rates and Actual Policies, Carnegie-Rochester Conference Series, eds. K. Brunner and A.H. Meltzer. 25:11-44.

Runkle, David E. (1987) "Vector autoregressions and reality," Journal of Business and Economic Statistics, 5:437-454.

Schwert, G. William (1987) "Effects of model misspecification on tests for unit roots in macroeconomic data," Journal of Monetary Economics, 20: 73-104

Shapiro, Matthew D. and Mark W. Watson (1988) "Sources of business cycle fluctuations," NBER Macroeconomics Annual, 111-148.

Sims, Christopher A. (1980) "Macroeconomics and reality," Econometrica, 48: 1-48.

Sims, Christopher A. (1986) "Are forecasting models usable for policy analysis?," Quarterly Review, Federal Reserve Bank of Minneapolis, Winter, 2-16.

Strongin, Steven (1995) "The identification of monetary policy disturbances: Explaining the liquidity puzzle," Journal of Monetary Economics 35, 463-497.

West, Kenneth D. (1990) "The sources of fluctuations in aggregate inventories and GNP," Quarterly Journal of Economics, 55:939-971. 
Appendix of Figures 